\title{
Correction to: Influence of Tissue Technology on Pannus Formation on Bioprosthetic Heart Valves
}

\author{
Tara J. Tod, ${ }^{1}$ Rachel A. Gohres, ${ }^{1}$ Mohammed Torky, ${ }^{2}$ Gregory A. Wright, ${ }^{1}$ Marie Lamberigts (i), ${ }^{3}$ \\ Willem Flameng, ${ }^{3}$ and Bart Meuris ${ }^{3}$ \\ ${ }^{1}$ Tissue Research, Edwards Lifesciences, Irvine, CA, USA; ${ }^{2}$ Cardiothoracic Surgery, Faculty of Medicine, Tanta University, \\ Tanta, Egypt; and ${ }^{3}$ Cardiac Surgery, Department of Cardiovascular Sciences, University Hospitals Leuven, Leuven, Belgium
}

(Published online 25 October 2021)

Correction to: Cardiovascular Engineering and Technology (ㄷ 2021) https://doi.org/10.1007/s13239-021-00530-1

This correction has been published to update the graphical abstract, Figs. 1, 4, and Table 1.
The original article has been corrected.

Publisher's Note Springer Nature remains neutral with regard to jurisdictional claims in published maps and institutional affiliations.

The original article can be found online at https://doi.org/10. 1007/s13239-021-00530-1.

Address correspondence to Marie Lamberigts, Cardiac Surgery, Department of Cardiovascular Sciences, University Hospitals Leuven, Leuven, Belgium. Electronic mail: marie.lamberigts@kulueven.be 